\title{
Value of Chamois (Rupicapra rupicapra L.) Trophies as a Part of Hunting Tourism Offer in the National Park Tara (Serbia)
}

\author{
Igor Ponjiger*, Dajana Lulić*, Milutin Kovačević**, Milan Malinić*** \\ Received: August 2015 | Accepted: September 2015
}

\begin{abstract}
Chamois dispersion and population in Serbia today is relatively small in contrast to many suitable habitats across the country. One of the last stable populations can be found in the Tara Mountain. It is also one of the last places in Serbia where hunting tourists can hunt chamois. Considering that, it can be said that Tara chamois population can represent an important attracting factor for hunting tourists, both domestic and foreign. This paper analyses the significance of this population on the increase of variety of hunting tourism offer on TaraMountain, but also in Serbia. Also, the values of trophies realized through hunting tourism are analyzed in terms of keeping track of the demand, but also as a way to monitor the population so it remains preserved in the future.
\end{abstract}

Key words: chamois, Rupicapra rupicapra, game trophy, hunting tourism, National park Tara

\section{Introduction}

Tara Mountain is located in the western part of Serbia, on the border with Bosnia and Herzegovina. It belongs to internal Dinarides and is a part of Serbian VlachMountains. Tara is a medium-high mountain with an average altitude of 1.200 meters and the highest peak, Kozji rid, 1,591 meters high. It is a typical forest area (over $85 \%$ of forest cover) with many endemic and endangered species (http://www.nptara.rs/).

It was declared a National park in 1981 with total area of the park being 19.175 ha and a protected buffer zone around it of 37.584 ha. Within NP Tara we can differentiate two spatially-functional characteristic areas: High Tara (11.562 ha) and Flat Tara (7.613 ha) (Radović, 2007).

The focus of this paper is chamois, which is one of the symbols of National park Tara. It is a native species and inhabits mostly canyon parts of the rivers Rača, Derventa, Drina and Brusnica. Chamois are social animals that live in larger or smaller herds, led by the female. Adult

* Society of Young Researchers of Department of Geography, Tourism and Hotel Management, "Branislav Bukurov" Trg Dositeja Obradovića 3, 21000 Novi Sad. Corresponding author: ponjiger@yahoo.com

** Department of Geography, Tourism and Hotel; Faculty of Sciences; University of Novi Sad; Dositej Obradović 3, 21000 Novi Sad

***National Park "Tara", MilenkaTopalovića 3, BajinaBašta, Serbia 
males are separated from the herd rarely gather in small herds, mostly in winter. At the time of mating all herds are joining. Mating is in November and the first half of December when there's the start of a fight between males. Populations are fragile, being extremely cautious animals, due to disturbances such as hikers, predators and avalanches (Ristić, 2013).

Horns of chamois are very reputable trophy among hunters, since this is one of the craftiest and cautious animals, and also their habitat is often very hard to reach. The trophies itself are the horns along with the part of the skull, or a stuffed head also with horns. Both males and females have relatively short, straight horns which are curved backwards near the tip. Males usually have thicker horns, which are also more curved backwards and have bigger span than the ones of the females. Since both male and female individuals have horns that represent trophies, but are slightly different, there are separate categories for assigning medals according to the number of points (Ristić, 2009).

Table 1. Range of the number of points per medals

\begin{tabular}{|c|c|c|c|}
\hline Gender & Bronze medal & Silver medal & Gold medal \\
\hline Male Chamois & $100-104.99$ & $105-109.99$ & $\geq 110$ \\
\hline Female Chamois & $95-99.99$ & $100-104.99$ & $\geq 105$ \\
\hline
\end{tabular}

Source: Ristić, 2009.

Determining of the sex of the individual is important before the process of assessment of the trophy. Next, all of the elements are measured. Those are the lengths of each horn, height, girth of the wider horn and span. Also, there are additional points for age, and deducting points for resin on the horns. Summation of all the elements gives the final score of the trophy.

The population in Tara is one of the last stable ones in Serbia. Therefore the status of the species on the national level is defined as VU (vulnerable). During the later half of the 2oth century the population had many up and downs, up until the 21st century when finally it reached its peak and stays that way for over a decade (Gačić, et al., 2010).

Historically, chamois was a frequent type of game, especially in eastern and western part of Serbia. Due to constant harassment, and deforestation, especially after World War II, and also poaching and animal husbandry, chamois was slowly disappearing from its ancient habitats. Chamois as allochthonous species, survived only in the western part of Serbia, on the Tara mountain, mostly in the canyon of Drina river (Marinović, Ristić, 2007)

As can be seen in Figure 1 the population was in a very bad condition during the 1960 os when first counting of the population occurred. Proper managing has led to an increase in population during the next two decades. However, in the 1990s the war in the neighboring Bosnia and Herzegovina, less than 10 kilometers from the National park, and poaching on a large scale led the population on the verge of survival, with only less than 100 individuals left. Since then the situation has improved drastically and the number has come close to its economic optimal number which is 380 according to Annual game management plan. Today the number of individuals is 370 according to the spring count in 2015.

According to Ristić (2004) hunting tourism is considered as "providing services for interested domestic or international hunting tourists, in order of organizing a visit to domestic hunting grounds for hunting, or observation and recording of game, with payment of certain compensation which is regulated in the pricelist of each hunting ground.

On the other hand, hunting tourism returns a significant portion of revenues earned to the hunting ground, which for the most part later focuses on the production and protection of wild animals, ie. the introduction of at least the same number of the individuals of certain 


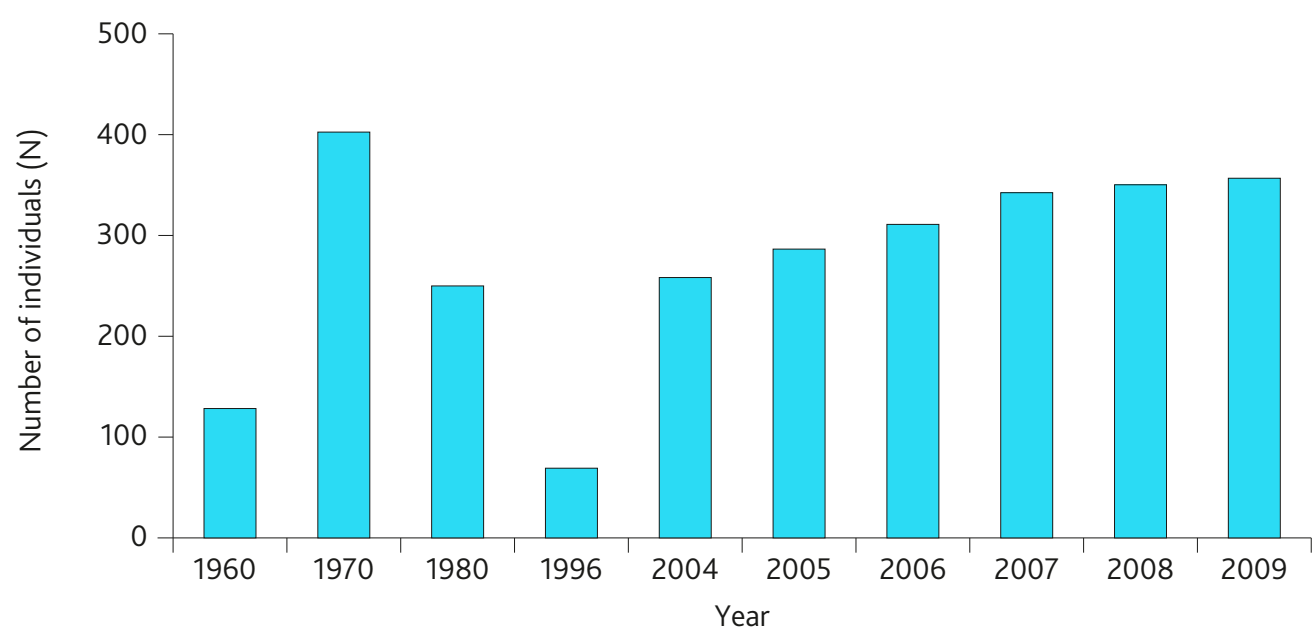

Figure 1. Dynamics of spring density of chamois population in the hunting ground "Tara" Source: Gačić, et al., 2010.

species of wildlife, as much as tourist hunting hunted. Part of funds gained through hunting tourism is directed at investments to improve the overall conditions for the implementation of hunting in hunting grounds (construction and maintenance of hunting-technical facilities, facilities for nutrition and accommodation of tourists, facilities for providing services for tourists in the hunting ground, transportation means and al.). Therefore, the main conclusion is that hunting tourism is the main generator of hunting (Štetić, 2007).

\section{Methods and data}

The managing of hunting ground and National park is done by public company "National park Tara". Its employees carry out the duties of monitoring and managing the wildlife. All of the data used in this paper were obtained from the professional service of the National park. Along with the Main hunting plan and Annual game management plans, the annual information about hunting quotas and game hunted through hunting tourism for the 2006-2015 period were also obtained. Trophies were measured in a standard way according to regulations of CIC (International Council for Game and Wildlife Conservation) and 126 chamois were measured in the observed period.

Methods used for the research consisted of collecting and analysing the data obtained from the professional service of the "National park Tara" and also from overview of the existing literature.

\section{Results and discussion}

Hunting tourism is one of the key factors in game management. Significant financial resources are being returned to the hunting ground this way. The main precondition for hunting tourism is a stable number of the game. As it was seen in Figure 1 the population number was steadily growing in the past decade. According to Annual game management plan for 2015-2016 hunting season chamoishas reached the number of 370 individuals in 2015. This means that certain number of individuals can be offered through hunting tourism. 


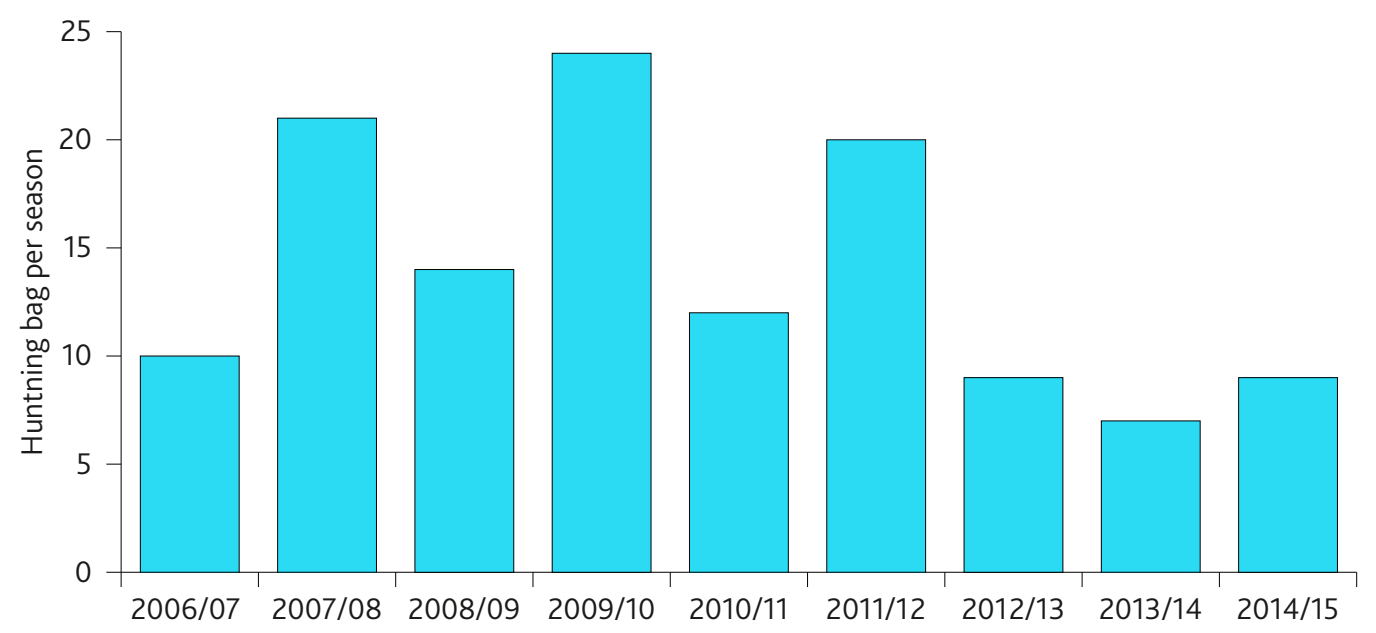

Figure 2. Hunting bag from 2006 to 2015

Source: Constructed based on the data obtained from public company "National park Tara"

Hunting bag during the entire observed period was 126 individuals and the annual hunting bag can be seen in Figure 2.

During nine hunting seasons, the number of hunted chamois reached its peak in 2009/2010 hunting season. Recent years show a certain decrease in overall hunting bag.

During the observed period, nine hunting seasons, 126 chamois was hunted, of which 76 were male and 50 were female. The sex ratio of hunted animals is 1: 1.52 in male chamois favor. Even though more male chamois was hunted, the gender ratio remains in the acceptable limits, with the ratio being 1:1, 1 in female chamois favor, according to the spring count in 2015.

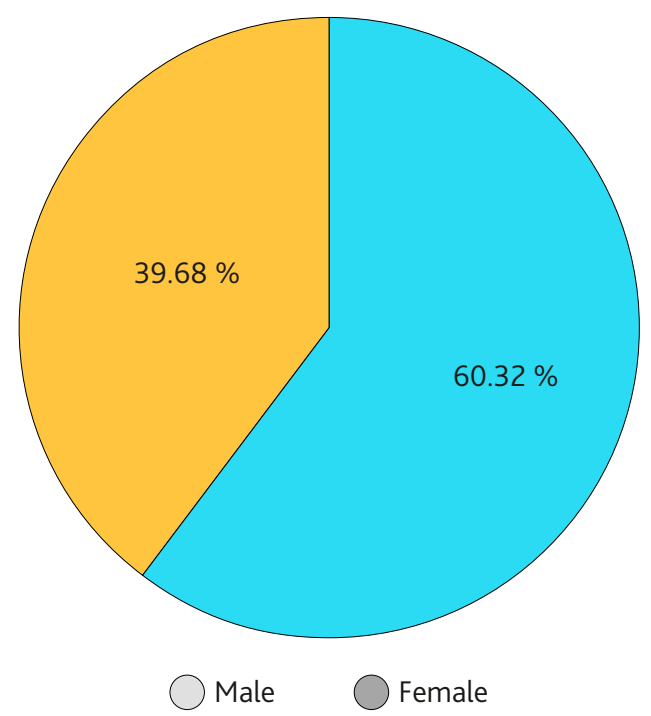

Figure 3. Ratio of hunted chamois by gender

Source: Constructed based on the data obtained from public company "National park Tara" 


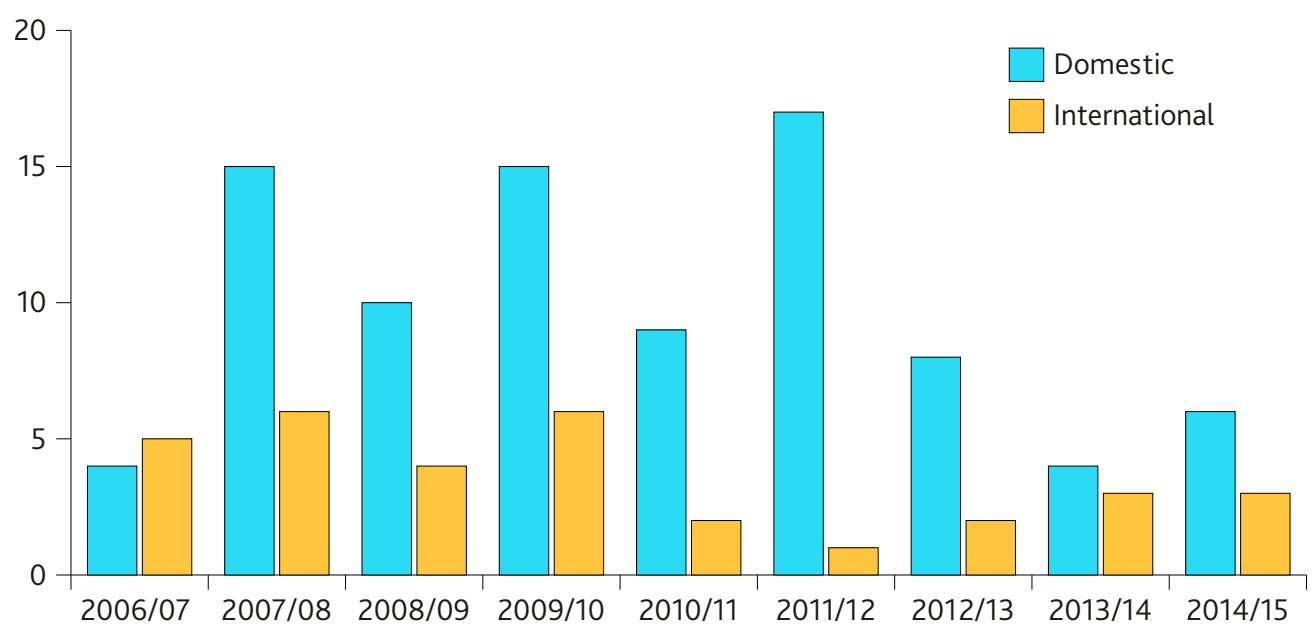

Figure 4. Number and origin of hunting tourist in the hunting ground "Tara"

Source: Constructed based on the data obtained from public company "National park Tara"

Hunting tourism offer represents appropriate number of attractive game, hunting tourism services and goods, available for placement on the market, in order to please the need of hunting tourist for hunting of preferable game. Most important part of hunting tourism offer is the game, because it is the main motive for hunting tourists (Prentović, 2006).

Total number of hunting tourists during the observed period was 120. As it can be seen in Figure 4 larger part in the total number of tourists consists of domestic tourists. This can be attributed to the fact that the hunting ground still hasn't positioned itself on the international market.

The following Figure 5 shows the average value of points of hunted chamois in hunting tourism from 2006 to 2015 . As it can be seen in the graph, the average number of points for last 9 hunting seasons is almost identical. The lowest average value recorded is in the hunting

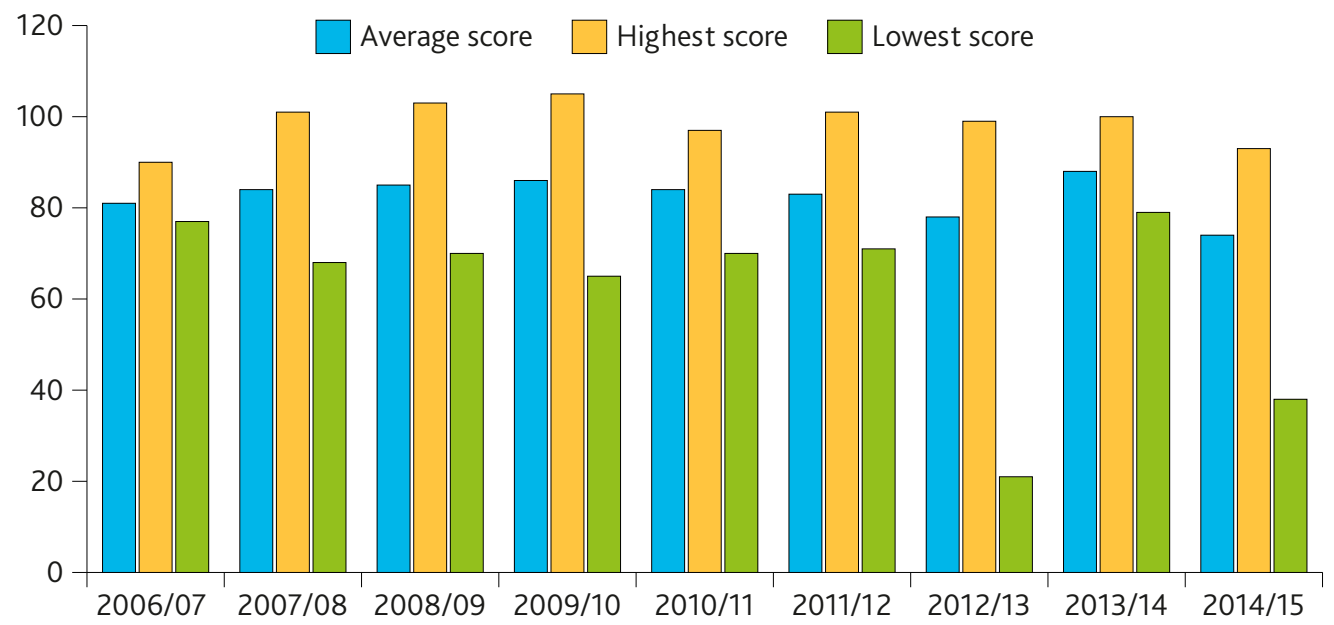

Figure 5. Average number of points for trophies of hunted chamois from 2006 to 2015

Source: Constructed based on the data obtained from public company "National park Tara" 
season 2014/2015, while the highest average value is recorded in season 2013/2014. The total average value of CIC points of hunted chamois is 83.24. As it can be seen from average values, foreign and domestic hunters prefer selective hunting in which points are not important. This kind of hunting makes significant financial income. Selective hunting in other European countries is practiced for a long time.

Trophy hunting of wild game is mostly performed on the most valuable capital game with time of hunting should be kept in mind (just after mating) and scope of hunting, which must be done so that it does not later lead to a decline in the trophy value of game (Main hunting plan).

Trophy hunting is usually done by members of the hunting association, or by hunting tourists. The overall volume of harvest is influenced by the real growth rate, above which hunting can't be realized, and also the possible migration that occur in the hunting ground.

Except trophy hunting, this hunting ground also offers selective hunting. Selective cull represents reduction of game that has bad hereditary qualities, condition of health, trophy values, weight, fur color, physical appearance, behavior and other characteristics that differ from the normal state in hunting ground. Also, this is the way to control the population gender and age structure. Selective cull needs to be conducted in younger categories of game, in the case of chamois, prior to the fifth year. Individuals that are extracted from the population are ones with small horns and weak physique, and also ones with broken horns (Jevremović, Jovančić, 2009).

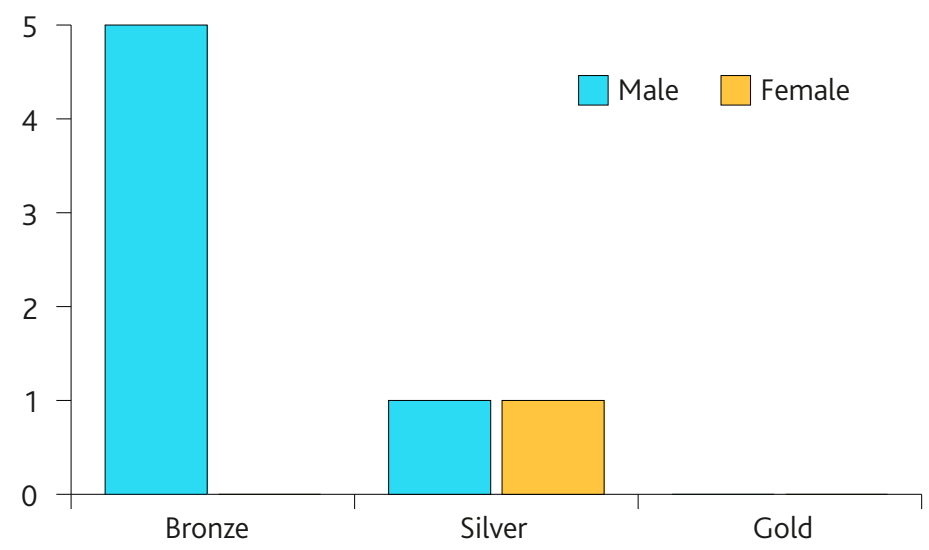

Figure 6. Overview of capital trophies of chamois in the observed period Source: Constructed based on the data obtained from public company "National park Tara"

As far as capital trophy chamois, for the last nine hunting seasons in this hunting ground hunting tourists hunted six capital trophy male chamois, five in bronze and one in silver medal, and one female chamois in silver medal. Considering the fact that this population was on the decline until the end of the last century, the results displayed in this paper show that today the population is much more stable and in better condition.

For the past three years a project "Strengthening of biological capacities and technical infrastructure for reintroduction of chamois to suitable habitats in Serbia" is being carried out on the territory of the hunting ground, so the results in that period need to be taken with reservations. The goal of the project is to capture and relocate certain number of individuals to habitats that chamois used to inhabit across Serbia. 


\section{Conclusion}

The population of chamois in Tara today is stable and has recovered from severe decrease of population during the last decade of the 2 th century. The work of the professional service is starting to show with the stable number of individuals in the population but also in the steady increase of the value of trophies for the past decade. Taking into account all of the facts, it can be said that the population is stable, but also vulnerable. Hunting tourism is declining, but this area still remains recognizable among hunting tourists, which are expected to continue to visit this destination. In the paper it was shown that the number of tourists fluctuates and that there is more domestic hunting tourist. Fact is that the population is still recovering and during the observed period progress can be seen in the number of game and also in the trophy value. In order to have even better results hunting ground "Tara" needs to position itself as one of the diverse hunting grounds and thus attract more tourists. As far as chamois population, hunting ground "Tara" has large national importance and needs to be managed sustainably.

\section{Acknowledgement}

We wish to express our gratitude to the National park Tara, especially the head of hunting service Milan Malinić, for providing us the necessary information and documents, and also for valuable advices and assistance during the writing of this paper.

\section{References}

Annual game management plan for 2015-2016 hunting seasonfor the Hunting ground Tara. (in Serbian)

Gačić, D., Lavadinović, V., Bjedov, V., Malinić, M. (2010). Chamois (Rupicapra rupicapra balcanica) management in the National park "Tara”, Forest ecosystems and climate changes, Belgrade.

Jevremović, M., Jovančić, S. (2009.) Hunting and wild game in hunting grounds of Serbia, Synopsis, Belgrade. (in Serbian)

Main hunting plan of hunting ground "Tara", valid 2007-2017. (in Serbian)

Marinović, Lj., Ristić Z. (2007). Potential habitats for chamois in the mountain areas of Serbia, Turizam 11, 239-241. (in Serbian)

Prentović, R. (2006). Basics of hunting, Department of Geography, Tourism and Hotel Management, Novi Sad. (in Serbian)

Radović, D. (2007). Evolving GIS at Tara National Park (Serbia)

Ristić, Z. (2004). Feathered game as a part of hunting tourism offer of Vojvodina, Department of Geography, Tourism and Hotel Management, Novi Sad. (in Serbian)

Ristić, Z. (2009). Evaluation of hunting trophies, Sajnos, Novi Sad. (in Serbian)

Ristić, Z. (2013). Game zoology and hunting taxonomy, volume 1, IK "Ljubostinja”, Trstenik. (in Serbian)

Štetić, S. (2007). Special forms of tourism, Belgrade. (in Serbian)

https://earth.google.com

http://www.nptara.rs 